\title{
Terminology Management at the National Language Service
}

Mariëtta Alberts, National Language Service, Department of Arts, Culture, Science and Technology, Pretoria, Republic of South Africa

\begin{abstract}
Terminology is a strategic resource in a multilingual country. It is the medium through which knowledge and information is disseminated. Through the use of correct, standardised terminology, effective scientific and technical communication skills are developed. A brief overview is given of terninology development in South Africa, with special emphasis on the work of the Terminology Division of the National Language Service. Aspects of present terminology practice such as terminology management, the nature of terminology and terminography, and work-flow procedure in a multilingual terminology office receive attention. To present training activities, initiatives and needs attention is also given.
\end{abstract}

Keywords: BILINGUAL, COMMUNICATION SKILLS, DISSEMINATION, DOCUMENTATION, DOMAIN, MULTILINGUAL, SOCIOLINGUISTICS, SOURCE LANGUAGE, STANDARDISATION, STANDARDISED TERMINOLOGY, SUBJECT FIELD, TARGET LANGUAGE, TECHNICAL DICTIONARIES, TECHNICAL LANGUAGE, TERMINOGRAPHER, TERMINOGRAPHY, TERMINOLOGIST, TERMINOLOGY, TERMINOLOCY DEVELOPMENT, TERMINOLOGY MANAGEMENT, TERMINOLOGY PRACTICE, TERMINOLOGY PRINCIPLES, TERMINOLOGY TRAINING

Opsomming: Terminologiebestuur by die Nasionale Taaldiens. Terminologie is ' $n$ strategiese bron in ' $n$ meertalige land. Dit is die medium waardeur kennis en inligting versprei word. Deur die gebruik van korrekte, gestandaardiseerde terminologie kan effektiewe wetenskaplike en tegnologiese kommunikasievermoëns ontwikkel word. 'n Kort oorsig word gegee van terminologieontwikkeling in Suid-Afrika, met spesiale klem op die werk van die Terminologieafdeling van die Nasionale Taaldiens. Aspekte van die huidige terminologiepraktyk soos terminologiebestuur, die aard van terminologie en terminografie en die werksvloeiprosedure in ' $n$ meertalige terminologiekantoor ontvang aandag. Aan huidige opleidingsaktiwiteite, -inisiatiewe en -behoeftes word ook aandag gegee.

Sleutelwoorde: BRONTAAL, DISSEMINERING, DOELTAAL, DOKUMENTASIE, DOMEIN, GESTANDAARDISEERDE TERMINOLOGIE, KOMMUNIKASIEVERMOENS, MEERTALIG, SOSIOLINGUISTIEK, STANDAARDISERING, TERMINOGRAAF, TERMINOGRAFIE, TERMINOLOGIE, TERMINOLOGIEBESTUUR, TERMINOLOGIEONTWIKKELING, TERMINOLOGIEOPLEIDING, TERMINOLOGIEPRAKTYK; TERMINOLOGIESE BEGINSELS, TERMINOLOOG, TWEETALIG, VAKGEBIED, VAKTAAL, VAKWOORDEBOEKE 


\section{Introduction}

The National Terminology Services (NTS) and State Language Services (SLS) of the Department of Arts, Culture, Science and Technology (DACST) merged on 1 April 1998 to form the new National Language Service (NLS).

With the merging of the two offices some aspects of the management of terminology and terminography changed. The office is now called the Terminology Division of the National Language Service.

The Terminology Division (TD) is the national office assisting the Government by providing terminology information in all the official South African languages. The TD documents, develops, standardises and publishes term lists covering various registers - the objective being to reduce ambiguity and misunderstanding, and thereby improving on the exactness of scientific and technical communication in the working environment.

The TD advises on national policy concerning technical language, establishes and evaluates norms for terminographic purposes, creates and implements standardised facilities and procedures to collect, document, systematise, standardise and disseminate terminological information for the different language groups in the Republic of South Africa, provides an information service on technical languages as well as on terminographic matters, co-ordinates, supports and facilitates projects for the development of technical languages, makes terminology facilities and products available to related information and communication systems and develops and manages the National Term Bank.

Originally resorting under the Science and Technology Branch of the Department of Arts, Culture, Science and Technology, the National Terminology Services (now Terminology Division) worked according to subject fields. Since then, the TD has been reintegrated under the National Language Service of the Arts and Culture Branch of the DACST and will henceforth also function according to language specific needs and will emphasise the development of the terminologies of the hitherto marginalised languages. The TD will prioritize projects with the objective of promoting scientific and technical communication in the African languages by enlarging and developing the various technical languages.

The centralised documentation of terms is important to avoid duplication and to promote standardisation. The TD acts as national facilitator recording the terminological input of various speech and subject communities in a central data bank. Terminological information can be obtained from this central office. In this way the TD serves the community and empowers them in communication.

The TD will become a clearing house for terminology work in South. Africa, since the demand for terminology increases rapidly. Unfortunately the TD does not have the personnel to cope with this demand. Various aspects 
concerning terminology and terminography management in the new NLS will receive attention in this article.

\section{Brief Overview on Terminology Development in South Africa}

The history of African language terminology in South Africa starts in 1928 with the formation of Language Committees - structures similar to language boards. These have changed over the decades in both structure and focus.

Since 1948 Language Boards have taken a fundamentally political outlook in composition, function and relation. These Boards were associated with "independent homelands" and similar political formations. Their political role was to present a picture of separate development, primarily of homeland structures. Some of these boards were accountable to the Chief Ministers and their Cabinets, some to the Departments of Education and Training and others to both the Ministers and the Departments. These Boards were funded mainly by the homeland governments and had representatives of these governments as members.

There were boards for every African language, though some would be duplicated for political purposes, as was the case in Transkei, Ciskei and Bophuthatswana (cf. Ntshangase 1996).

Translators started documenting English and Afrikaans terms on cards in the fifties, at the erstwhile Language Bureau of the Department of Culture (later the Department of National Education). Later, a Terminology Division developed within the Language Bureau. Terminologists were appointed to excerpt terms from documents and to systematise and to standardise the terminology of various subject fields. A variety of bilingual term lists and technical dictionaries were published.

Language bureaux for institutions such as the South African Defence Force (SADF), the Suid-Afrikaanse Akademie vir Wetenskap en Kuns (SAAWK), the South African Iron and Steel Industrial Corporation (Iscor), Municipalities, South African Bureau of Standards (SABS), the South African Broadcasting Corporation ( $S A B C)$, etc. that employed translators, also had a few terminologists to excerpt the terminology of the relevant institution. A Coordinating Terminology Board (COTERM) was formed in 1971 to co-ordinate the terminology endeavours of the various offices.

In 1976 the Terminology Division of the Department of National Education amalgamated with the Vaktaalburo of the SAAWK to form a new Terminology Bureau. This Bureau was later named the National Terminology Services (NTS) of the Department of Arts, Culture, Science and Technology (DACST) and the office became the official national office to document terminology. In April 1998 the NTS and the State Language Services of DACST amalgamated to form the National Language Service (NLS).

Although the NTS and its predecessors in the past primarily compiled bilingual, bidirectional technical dictionaries, it was realised that there was a 
pressing need for terminology in the various African languages. The NTS therefore began research into word-forming principles in the indigenous languages. It was decided to start with the compilation of multilingual technical dictionaries in all national South African languages and with the addition of extended information such as definitions and explanations.

Since 1994, African language terminologists have been employed to document African language terminology in a variety of subject fields. Multilingual terminology lists such as Weather Terms, Basic Health Terms, HIV/AIDS Terms, Building Terms, Election Terminology, Banking Terms, Commercial and Financial Terms and Computer Terms are being compiled, as well as lists on subjects such as Indigenous Birds, Indigenous Mammals, Frail Care, Personnel Administration, Basic Physics, Basic Sewing, Basic Agriculture, Biology, Zoology, Sewing and Fashion, Health Education, and lists for various school subjects.

The Terminology Division of the NLS provides a base of knowledge for all language groups on National, Provincial and Local Government level and also for all other spheres of technical and scientific communication. The office serves the whole community. This includes all levels of communication in all registers in which terminology of the official languages is needed - from grass-roots level to the higher echelons of science and technology.

The Terminology Division of the NLS also works in close collaboration with outside multilingual projects such as the Legal Terminology Project of the Centre for Legal Terminology in African languages (CLTAL), the Chemistry Dictionary which is a combined effort by the SAAWK and the University of Pretoria, the revision of the 1967 Arts Dictionary by the SAAWK, terminology for the Correctional Services, etc. Work on a few outside bilingual projects such as the Music Dictionary, the Oceanography project, and dictionaries on Education, Physics, Geography, Dietetics, Statistics, Ophthalmology, Political Sciences and Mechanical Engineering will be completed soon. The Terminology Division also assists with international projects such as a multilingual project of the European Union as well as a project for the International Organization for Unification of Terminological Neologisms (IOUTN) that manages a World Bank of International Terms (WBIT)'.

The Terminology Division of the NLS works in close collaboration with the Pan South African Language Board (PANSALB) and its related bodies. PANSALB is an independent statutory body appointed by the Senate in March 1996 in terms of the Pan South African Language Board Act. Its work is to monitor the observance of the constitutional provisions and principles relating to the use of languages as well as the observance thereof in and content of any existing and new legislation, practice and policy relating to language matters. It has a broad function and will ensure that politicians in Parliament are guided by a body with nonpolitical knowledge of relevant multilingual issues in South Africa (cf. LANGTAG 1996). 
According to its Act, PANSALB has to establish provincial language councils and language-specific bodies. The PANSALB Act was revised in 1999 to incorporate the establishment and management of national lexicography units for each of the official South African languages.

The Terminology Division usually works from a specific source language (SL). In South Africa the source language is usually English and translation equivalents have to be provided in the other official South African languages. When providing or coining translation equivalents for SL terms, terminologists consult linguists and subject specialists. The NTS used to work in close collaboration with the old Language Boards, but at present the terminologists of NLS consult the language bodies already established by PANSALB.

\section{Terminology Division}

From 1 April 1998 the Terminology Division (previously National Terminology Services) functions as a subdirectorate of the National Language Service of the Department of Arts, Culture, Science and Technology. It is the largest (and at the moment the only) organisation in South Africa devoting its time entirely to terminology work.

The mission of the Terminology Division (TD) is to assist in the development and modernisation of the technical vocabularies of the official languages of South Africa.

The aim of the TD is to support Government in the formulation, development, implementation and maintenance of a national policy and strategies concerning technical languages with a view to the promotion of scientific and technical communication in all South African language communities.

The objectives of the TD are to support the Government in the formulation, planning, development, implementation and maintenance of a national policy and strategies concerning technical languages with a view to the promotion of scientific and technical communication in all South African language communities, to render a terminology service for the advancement of the official languages at a national level by conceptualising, creating and standardising terminologies on behalf of all South African language groups, to develop the required structures and facilities needed to meet the requirements of the indigenous language communities, to facilitate and co-ordinate terminology development and other technical language projects and to develop, manage and maintain a computerised information-oriented terminological database (the National Termbank) to further the dissemination of technical language information.

Primarily bilingual (English/Afrikaans) technical dictionaries were compiled in the past, but at present there is a pressing need for multilingual dictionaries with additional information such as definitions and explanations in especially the various African languages, in various domains and at various levels of communication. The TD therefore aims to document technical and 
scientific concepts and definitions and provide equivalents (e.g. by development or elaboration of terminology) in all the official languages, and in different domains - from grassroots level to the highest tertiary level.

The TD has the infrastructure, but unfortunately not enough personnel to carry out this task. It employs language practitioners (terminographers and terminologists) for all the official South African languages in order to produce the relevant terminology products.

The TD focuses on providing a service to the community. Clients of the TD includes all persons in South Africa concerned with education and training as well as interpreters, translators, copywriters and journalists, i.e. all people in career groups involved in communication in one way or the other. One important function of the TD is to provide a terminology information service.

The TD aims to document technical and scientific concepts in various subject fields and related domains. Translation equivalents are provided in all the official South African languages with a view to the promotion of the standardisation of technical terms of those languages. The terminology information is disseminated in various ways: by conventional means such as draft terminology lists, glossaries and technical dictionaries, or by electronic means such as CD-ROM and online (i.e. the National Termbank and, in future, the Internet).

Terminology lists are compiled according to priorities determined by needs assessments. The TD sends out questionnaires to a wide range of target groups to determine the varied terminology needs of the broad community.

Extensive research has been done on copyright issues affecting terminology in order to determine the legal position of the TD with regard to the products created by this office. It was found that the dictionaries and term lists produced by the TD are of an original nature and that the publication of these will therefore not constitute an infringement of the copyright of the sources consulted.

The MultiTerm Plus database system forms the basis of the restructured National Termbank which will enable the TD to disseminate terminological information electronically. All activities of development in the field of computer systems take place in accordance with standards as set by the International Standardisation Organisation (ISO). The unique demands of the African languages with regard to terminology processing are attended to in collaboration with the ISO.

Computer assistance from the TD is available to several projects inside the TD as well as to projects by individuals or institutions outside the NLS. The computer assistance consists of the alphabetisation and conversion of data sets, the writing of synonyms as headwords (cross-referencing), the retrieval of data, the printing of work and draft lists, and the provision of master copies for printing.

The TD is at present working on a variety of multilingual terminology lists on various subjects such as Geography, Physics, Basic Science, Statistics, Com- 
puters, Meteorology, and a variety of lists concerning terminology related to the Building Industry, Political Sciences, Law, Public Administration, Mechanical Engineering, Education, Olympic Games, Mammals, Dietetics, Frail Care, Basic Health, HIV/AIDS, Agriculture, etc.

The TD provides guidelines on both terminographic and terminology matters by means of desktop publications. The predecessor of the TD - the National Terminology Services (NTS) - used to regularly update and publish a catalogue providing information about existing scientific and technical dictionaries on a regular basis. The NTS also published the catalogue Language Resources.

The NTS used to publish the newsletter Termbroker at regular intervals with the aim of distributing and co-ordinating terminology and terminography information for all indigenous languages.

The TD strives to serve the government and the general public by making terminological information available. This forms an important part of the community service rendered by the TD to empower people in scientific and technical communication.

The TD is increasingly acting in a supporting capacity through guidance, project facilitation and outside liaison. The TD aims to introduce the activities and facilities of the TD and also promotes the availability and advantages of the online National Termbank.

In order to increase public awareness of scientific and technical terminology, the TD has shown its terminological databank to the public at two recent Science and Technology exhibitions. The exhibitions also previewed the online National Termbank which is at present being developed and which will be available on the Internet. The TD also participated in a series of exhibitions for the Year of Science Road Show.

\section{Terminology Management}

The TD used to be divided into four subject-related sections, namely:

- Natural and Computer Sciences (i.e. Physics, Chemistry, Computer Science, Building Science, Statistics, Geology, Geography, Engineering, etc.),

- Human and Social Sciences (i.e. Personnel Administration, Psychology, Sociology, Legal Sciences, Political Sciences, etc.),

- Life and Agricultural Sciences (i.e. Biology, Agriculture, Zoology, Botany, Dietetics, Basic Health, Frail Care, HIV/AIDS), and

- Commercial Sciences (i.e. Financing, Banking, Accountancy, etc.).

Since 1994 a separate section for the development of the African Languages has been established and the sections Human and Social Sciences and Commercial Sciences have been merged to form a section Commercial and Human Sciences. 
Two to three terminographers did group work for the respective projects in each subject-related section, such as the basic terminographical part of excerpting, documenting the source language (usually English), defining the concepts, etc. The terminologists of the African languages section then received a work list on a specific subject field (i.e. Biology) to provide the translation equivalents in his/her first language. They also translated source language definitions into the various target languages. This procedure implied that the African language terminologists were merely translating terms and definitions.

To correct this it was decided that at least two language practitioners would work together as team on a given project in future. One member of the team would be a terminographer (he/she could be a speaker of any of the official languages, but should be proficient in the source language) and the other member a terminologist (mother-tongue speaker of one of the target languages). They deal with all aspects concerning the project (e.g. excerption, systematisation, documentation, defining, committee meetings (subject specialists and linguists), final editing, proofreading, front and back matter, etc.). They share the responsibilities for the project and meet deadlines.

Terminologists never work in isolation. They consult subject specialists when dealing with the concepts and terms of a specific subject field and also with linguists, mother-tongue speakers, and language committees when supplying translation equivalents or when coining terms.

\section{A Model of the Work Flow within the Terminology Division}

\subsection{Types of requests for terminology}

The TD decides on terminology projects in response to needs assessment studies and/or requests:

- The section Systems Development and Research of the TD conducts needs assessment studies in collaboration with various stakeholders and identifies client needs in the field of terminology, and/or

- The Head of TD receives a request from a client, institution or other user of the language for a terminology list in a specific subject field or domain.

\subsection{The route ${ }^{2}$ the project takes within the Terminology Division}

5.2.1 The request is referred to the Service Co-ordinator (researcher of Systems Development and Research responsible for updating the project manager database on which all the terminology projects are listed) who

- liaises with the client in collaboration with the Terminology Co-ordinator (terminologist to co-ordinate terminology projects within the Termi- 


\section{HEAD OF TERMINOLOGX DIVISION}

$\Leftarrow \pi+S L+D E F+10 T L s+D E F)$

LANGUAGE INFORMATION PACKAGING (Print dictionary $(D T P)=X+S L+D E F+10 T L s+D E F)$ (e.g. multilingual explanatory dictionary, Term bank, Internet)

\section{TERMINOLOGY SECTION}

TERMINOGRAPHY SECTION

(excerpt SL, define SL)

(SL = Eniglish)

(Supply 1x TL (Afrikaans translation equivalent + definition)

$$
\Uparrow
$$$$
X+S L+D E F+1 T L+D E F
$$

Natural Life

Human \& Commercial

Sciences Sciences

Sciences

$\Downarrow$

CONSULTATION: SUBJECT SPECIALISTS

LINGUISTS (Eng + A(r) LANGUAGE USERS

TERMINOLOGY SECTION NLS TRANSLATORS (supply translation equivalents in 9 TLs)

(supply definitions in TLs)

$$
\text { (TLs }=9 \text { Official South African languages) }
$$

$\Rightarrow$

$X+S L+9$ TL $s+D E F$

Sesotho isiXhosa Xitsonga Tshivenda

Sepedi isiZulu

Setswana isiNdebele

Siswati $\Downarrow$

CONSULTATION: SUBJECT SPECLALISTS

LINGUISTS LANGUAGE USERS

$\Leftrightarrow$ TERMINOGRAPHY SECTION NLS TRANSLATORS 
nology Divisions) and with the relevant Section Head to establish the detailed specifications pertaining to the envisaged project and completes the project registration form during the interview with the client,

- finds out whether a similar project is running somewhere else and contacts the compilers who are responsible for the project to establish a relationship of sharing information and uniting the efforts to produce a terminology list,

- writes a report on the feasibility of the project and submits it together with the completed project registration form to the management of the Terminology Division for consideration, and

- adds the information pertaining to each project to the project database and updates the database at regular intervals.

5.2.2 The TD Management (the Head of the TD plus Section Heads) discusses the project in depth and compares it to the priorities determined by the latest national needs assessment study. The TD Management approves, outsources or rejects the project and puts it on a priority list once it has been approved.

Each section within the TD indicates whether it will be possible to meet the requirements and deadlines set for the project, namely:

- Systems Development and Research (SD\&R),

- African Languages Section (ALS),

- Terminography Section (TS) (the subject-specific sections), and

- Language Information Packaging (LIP).

5.2.3 All the information pertaining to the project is documented on the project manager database (run by SD\&R), whether the TD Management approves the project or not, together with the reasons for rejection. It serves as a future reference should the Terminology Division be in the position to work on the project at a later stage. SD\&R will register the projects.

5.2.4 Should TD Management approve the project, the following steps are followed:

- The information is given to the relevant section to prepare the list in the source language (including the information requested by the client).

- If the source language of the request (e.g. documentation on a specific subject, etc.) is in English or Afrikaans, the project goes to the relevant subject-specific section to document the terminology and to supply definitions in the source language. A draft list then goes to the African Language Section for translation equivalents and definitions and will at this 
stage also be provided with Afrikaans translation equivalents and definitions.

- If the source language is any one of the African languages, the project goes directly to the African Languages section to excerpt the terms, document them in the given source language and provide the terms with definitions in the source language. The terminologists working on the project also supply translation equivalents and definitions in English and then give the draft list to the other African language terminologists and the subject-specific section for verification and provision of the required translation equivalents and terminological information required for Afrikaans.

- The relevant Terminography Section forms a subject committee of specialists in the specific domain to assist with the terms and definitions if necessary. The terminographers working in the subject-specific sections may from time to time be asked to work across subject fields should the need arise.

- Each terminologist/terminographer also works on his/her own project. The compiler (terminologist/terminographer) excerpts the terminology, documents the terms and provides the terms with definitions. In addition the compiler supplies the English translation equivalents and definitions to each term in the source language. The compiler discusses the terminological information of his/her project with subject specialists and linguists before finalising the draft lists that will be submitted to the Section Head for approval. After completion of each individual list, the draft lists go to the terminologists/terminographers of the other languages to be provided with translation equivalents and definitions. With each terminologist/terminographer having his/her own project, they take charge of the management of such a project and are able to carry the project through the various developmental phases. This forms part of the in-house training of all terminologists/terminographers.

- On national projects, the Terminography Section (i.e. the subject-specific section) and the African Languages Section work on the list in tandem. As soon as the Terminography Section has completed a considerable number of entries (e.g. 50-100) in the source language, the head of the specific Terminography Section informs the co-ordinator of the African Languages Section.

- The work is allocated to the relevant African language terminologists to provide equivalents and/or provide or translate definitions. (All the languages may not be requested.)

- Whilst working on the list, the African language terminologists should either form an editorial committee or consult with other knowledgeable collaborators such as linguists or subjectispecialists with a knowledge of the specific language to assist them with their work and to verify the terminology. 
Progress is reported to the head of the specific section that co-ordinates the specific project on a weekly basis on a prescribed form.

This information is submitted to the Service Co-ordinator to update the progress of the project on a monthly basis.

After the completion of the work, the section co-ordinating the project ensures that the information on the database has been entered correctly and supplies LIP with the specifications for preparing printouts for proofreading.

- The responsible terminologists (of all eleven official languages) have to proofread their own languages and check for orthography, spelling mistakes, omission of diacritics or punctuation marks, etc.

- After this step has been completed, the section co-ordinating the project requests LIP to prepare a master copy of the document for the client.

- The document is handed over to the client who can disseminate the document as such or publish a dictionary.

\subsubsection{Responsibilities}

The Section Head in the African Languages Section is responsible for all terminology projects and terminography work that have to be conducted by the mother-tongue terminologists in the nine official African languages.

Section Heads in the Terminography Sections (subject-specific sections) are responsible for the work of the English/Afrikaans terminologists and terminographers.

- When a Terminography Section has the assistance of the African language terminologists to supply target language equivalents for the African languages for a national project, it is the responsibility of the relevant section head, or his/her deputy to arrange a meeting with the terminologists concemed on a specific time to request them to do the work and to discuss problems emanating from the list with them after consultation and in collaboration with the co-ordinator African languages.

- It is the responsibility of the Terminography Section Head concerned or his/her deputy to provide the terminologists with the information as to where to find the data (the name of the filter for the MultiTerm software package), and to provide a hard copy of the list each time the list has been updated or when a new list has been produced.

The section Systems Development and Research is responsible for research and development studies related to the field of terminology.

The section Language Information Packaging manages the National Termbank and the MultiTerm database. This section handles all publications related to terminology work. 


\section{Training in Terminology and Terminography}

Since terminology is the vehicle for disseminating information, there is a dire need for trained terminologists and terminographers. Each subject field or domain (area of science, technology or work place) uses its own terminology. This terminology needs to be systematised, documented, and disseminated with a view to eventual standardisation. Only then will it be possible to communicate effectively. Terminologists can assist the subject specialists and language workers working in various subject fields or domains to document their terminology and to provide them with multilingual terminology lists.

One therefore not only needs trained terminologists to document terminology in the source language (usually English), but in order to facilitate proper communication one also needs African language terminologists to provide translation equivalents in the ten other official languages.

To my knowledge there is no institution or organisation in South Africa other than the NLS employing terminologists. In several language offices (local or provincial), translators or interpreters or other language workers sometimes document terms (institutionalised terms), but they are not formally employed as terminologists.

Throughout the country there is a gradual decline in the number of corporate language offices - and therefore also a decline in in-service training opportunities for potential terminologists. Without the support, supervision and assistance of experienced terminologists, new terminologists will find it extremely difficult to work at a standard that will satisfy the users of dictionaries and maintain the standards of the profession.

Four levels of terminology training can be distinguished:

- tertiary training in theory and principles of terminology,

- in-house terminology training,

- training of potential terminologists, and

- training of collaborators (language workers and subject specialists).

\subsection{Tertiary training in theory and principles of terminology}

Training in the theory and principles of terminology currently receives little attention where it forms part of the lexicography or translation modules at South African universities and technikons. The first postgraduate course in the principles and practice of terminology and terminography has been introduced in 2000 at the Department of African Languages, University of Pretoria.

The training of terminologists and terminographers should receive much more attention at tertiary level. The training should be done either in language departments (e.g. English, Afrikaans or African Languages) or in linguistics departments. "It should be an optional topic that students can take as part of their undergraduate studies," states a LANGTAG report (LANGTAG 1996: 82). 
"Training should include basic lexicography, terminography and translation studies. Students can then specialise in their Honours studies."

\subsection{In-house terminology training}

All the terminologists at the TD have undergone in-house training. During this training, all aspects of terminology work are dealt with. The terminologist/terminographer is trained in theoretical as well as practical principles to carry a project through all the stages of the terminographical process.

\subsection{Training of potential terminologists}

A potential terminologist should have the opportunity to receive appropriate training before he/she enters the profession. It is sensible that such training should be a combination of tertiary training and intensive training given by a national terminology office such as the Terminology Division of the National Language Service.

\subsection{Training of collaborators (language workers and subject specialists)}

Apart from in-house training sessions the TD offers some training sessions to individuals and bodies outside the TD. The purpose of these sessions is to elucidate the principles underlying terminology work. The training also includes practical sessions. Part of the training involves the illustration of computer applications in processing terminology and terminography.

Trainees are language workers or subject specialists with a desire to know how to document and systematise the terminology they encounter on a daily basis. These collaborators can inter alia assist the national terminology office by

- identifying terms in their working environment,

- documenting these terms according to basic terminographical principles to be entered into the National Termbank,

- answering terminology queries,

- providing translation equivalents in the official South African languages according to basic word-forming principles,

- coining new terms,

- commenting on draft terminology lists, and

- verifying the translation equivalents supplied by the Terminology Division with first language speakers.

Due to a lack of personnel, the TD cannot meet all the terminology needs nationwide. The office aims to extend the training programme in the near future. Various workshops and winter schools (with terminology experts from 
abroad as trainers) are planned to train collaborators in the principles and practice of terminology work. Such training will enable collaborators to work according to fixed terminological procedures and provide the National Term Bank with terminology related to their various specialist fields and domains. The TD will then be in a position to serve as a clearing house specialising in the documentation and dissemination of terminology in all official languages.

"The grassroots creativity of every speech community should be exploited and channels should be created to enable new terms at this level to be introduced into the central termbank," emphasises a LANGTAG report (LANGTAG 1996: 84). "For instance, schools, universities, newspapers, local administrations, etc. should be encouraged to send in their new terms to the Terminology Division."

\section{Conclusion}

Several factors influence the development of terminology in the African languages of South Africa. Most of these are sociolinguistic factors. In the past, terminology development in South Africa was hampered by a number of ideological, historical, and educational factors, such as the language policies adopted in the Republic of South Africa (RSA) (Mtintsilana and Morris 1988: 109). With English and Afrikaans as the official languages in the RSA up to 1994 , the State actively supported terminology development in Afrikaans to try to ensure parity with English.

Since 1995, structural and policy factors have affected the terminology practice in South Africa. Some of the language bureaux have either been dissolved or scaled down to perform smaller tasks. The State has also accepted the responsibility to develop and promote African languages.

Government policy in language promotion before 1994 stipulated that the promotion of the African languages was the task of the former national states and the self-governing regions, and not that of the South African Government.

The terminologist working in a multilingual society such as South Africa today deals with conflicting situations. The African terminologies should be developed to enhance the multilingual heritage of the country, but there are too many languages to make this practical and economically viable. There are also very few trained terminologists and even less terminology posts available. There is at present only one training institution offering an official course in terminology. Aspects relating to terminology principles are dealt with in courses such as translation or lexicography, but terminology receives too little attention in these courses to be of any value. The Terminology Division of NLS offers in-house training. If South Africa wishes to solve its communication problems through multilingual terminology in a variety of subjects or domains, the Terminology Division of NLS will have to offer terminology training to people interested in this profession. 
These matters emphasize the importance of the Terminology Division as an organisation working on a national basis to modernise and document the various technical vocabularies used in South. Africa by compiling multilingual technical dictionaries and by providing terminology training to colleagues in the field of terminology.

\section{Notes}

1. The IOUTN has been affiliated to the United Nations as a nongovemmental organisation since 1987. The IOUTN affiliates philologists, linguists and specialists in various fields of science and technology who are interested in problems of transnationalisation and the dissemination of specialised terminology.

The main task of the IOUTN is to encourage the borrowing of specialised terminology from the language of its creators and to stimulate a consciousness in all countries that this action is in every nation's interest. The IOUTN publishes glossaries and vocabularies to facilitate the work of translators, interpreters, writers and workers in various domains. It aims to transfer all the latest specialised terminology to less developed and developing countries. The WBIT within the IOUTN engages in accumulating and storing intemational teminology and specialised neologisms using the materials supplied by more than 200 members from 40 countries all over the world. Incidentally, it is the first term bank in the world to hold a catalogue of multilingual intemational terms (Stoberski 1998: 6).

2. See work-flow diagram on p. 242.

\section{Bibliography}

Alberts, M. 1983. Aspekte van die rekenarisering van vakwoordeboeke. M.A. Dissertation. Pretoria: University of Pretoria.

Alberts, M. 1990. 'n Bepaling van Afrikaanse vakleksikografiese behoeftes. D.Litt. et Phil. Thesis. Pretoria: University of South Africa.

Alberts, M. 1996. The Harmonisation of Nguni and Sotho: Terminological Perspectives. Paper read at the Pre-Seminar Colloquium on the Harmonisation and Standardisation of African Languages for Education and Development, 11-13 July 1996, University of Cape Town, Cape Town.

Alberts, M. 1997a. Legalese: South Africa's 12th Official Language? Paper read at the Seminar on Language in Court at the Former Venda Parliament (Government Buildings), Thohoyandou, 1617 May 1997.

Alberts, M. 1997b. Legal Terminology in African Languages. Lexikos 7: 179-191.

Alberts, M. 1998. The Harmonisation of Nguni and Sotho: Terminological Perspectives. Prah, K.K. 1998: 229-242.

Alberts, M. 1999. Overview of Current Initiatives in Terminology. Tutorial presented at the Tenth Intemational Conference held by ALASA, 6 July 1999, University of South Africa, Pretoria.

Alexander, N. 1989. Language Policy and National Unity in South Africa/Azania. Cape Town: Buchu Books. 
CaIteaux, Karen. 1996. Standard and Non-Standard African Language Varieties in the Urban Areas of South Africa. Stanon Main Report. Pretoria: HSRC.

Carstens, A. 1997. Introduction to Terminology and Terminography. Pretoria: University of Pretoria.

Cluver, A.D. de V. 1974. Voorstelle ter normering van die voorstukke van vakwoordeboeke. Pretoria: UNISA.

Cluver, A.D. de V. 1987. A Sociolinguistic Approach to the Study of Technical Languages. Logos 7(2): $13-30$.

Cluver, A.D. de V. 1989. A Manual of Terminography. Pretoria: HSRC.

Cluver, A.D. de V. 1994. Preconditions for Language Unification. South African Journal of Linguistics, Supplement 20: 168-194.

Cluver, A.D. de V. 1996. Language Development. Proceedings of a LANGTAG Workshop on Issues in Language Development: Focussing on the Future of the Apartheid Language Boards and the Harmorisation and Development of African Languages, Pretoria, 28 March 1996.

Cluver, A.D. de V. n.d. Preconditions for Language Unification. Private paper.

Felber, H. 1982. Basic Principles and Methods for the Preparation of Terminology Standards. Vienna: Infoterm.

Felber, H. 1996. Worldwide Efforts to Establish Principles and Methods in Terminology and Terminography. TermNet News 54/55: 24-25.

Fourie, D.J. 1994. The Rejection of Terminology: Observations from the African Languages. South African Journal for African Languages 12(1): 11-15.

Galinski, C. and K.-D. Schmitz 'Eds.). 1996. TKE '96: Terminology and Knowledge Engineering. Frankfurt/M: Indeks Verlag.

LANGTAG. 1995. Towards a National Plan for South Africa. A Report of the Language Plan Task Group. Pretoria: Department of Arts, Culture, Science and Technology.

LANGTAG. 1996. Information on the Language Plan Task Group (LANGTAG). Pretoria: State Language Services, Department of Arts, Culture, Science and Technology.

Louwrens, L.J. 1994. Dictionary of Northern Sotho Grammatical Terms. Pretoria: Via Afrika.

Louwrens, L.J. 1997. On the Development of Scientific Terminology in African Languages: The Terminographer's Dilemma in a New Dispensation. Lexikos 8: 248-250.

Msimang, C.T. 1994. Language Attitudes and the Harmonisation of Nguni and Sotho. South African Journal of Linguistics, Supplement 20: 147-167.

Msimang C.T. 1996. The Nature and History of Harmonisation. Proceedings of a LANGTAG Workshop on Issues in Language Development: Focussing on the Future of the Apartheid Language Boards and the Harmonisation and Development of African Languages, Pretoria, 28 March 1996.

Mtintsilana, P.N. and R. Morris. 1988. Terminography in African Languages in South Africa. South African Journal of African Languages 8(4): 109-113.

Nahir, M. 1984. Language Planning Goals: A Classification. Language Problems and Language Planning 8(3): 294-327.

Nkondo, C.P.N. 1987. Problems of Terminology in African Languages with Special Reference to Xitsonga. Logos 7(2): 69-78.

Ntshangase, D. 1996. Working Document: Future of the Present Language Boards. LANGTAG Subcommittee on the Development of (South) African Languages, 20 February 1996.

Ohly, R. 1987. Corpus Planning, Glottoeconomics and Terminography. Logos 7(2): 55-67. 
Poulos, G. and L.J. Louwrens. 1994. A Linguistic Analysis of Northern Sotho. Pretoria: Via Afrika.

Prah, K.K. 1998. Between Distinction and Extinction. The Harmonisation and Standardisation of African Languages. Johannesburg: Witwaterșrand University Press.

Sager, J.C. 1990. A Practical Course in Terminology Processing. Amsterdam: John Benjamins.

SATI. 1996. Bulletin 6: 1-2.

Stoberski, Z. 1998. Multilingual Dictionary of International Terms. Warszawa: World Bank of International Terms (WBIT) within the International Organization for Unification of Terminological Neologisms (IOUTN). 